\title{
Neuroimaging in patients with COVID-19: a neuroradiology expert group consensus
}

\author{
Stéphane Kremer ${ }^{1,2} \cdot$ Simonetta Gerevini $^{3} \cdot$ Ana Ramos $^{4} \cdot$ François Lersy $^{1} \cdot$ Tarek Yousry $^{5,6} \cdot$ Meike W. Vernooij $^{7}$. \\ Nicoletta Anzalone ${ }^{8} \cdot$ Hans Rolf Jäger ${ }^{5,6}$
}

Received: 8 July 2021 / Revised: 27 November 2021 / Accepted: 30 November 2021 / Published online: 19 January 2022

(c) The Author(s), under exclusive licence to European Society of Radiology 2022

\begin{abstract}
Neurological and neuroradiological manifestations in patients with COVID-19 have been extensively reported. Available imaging data are, however, very heterogeneous. Hence, there is a growing need to standardise clinical indications for neuroimaging, MRI acquisition protocols, and necessity of follow-up examinations. A NeuroCovid working group with experts in the field of neuroimaging in COVID-19 has been constituted under the aegis of the Subspecialty Committee on Diagnostic Neuroradiology of the European Society of Neuroradiology (ESNR). The initial objectives of this NeuroCovid working group are to address the standardisation of the imaging in patients with neurological manifestations of COVID-19 and to give advice based on expert opinion with the aim of improving the quality of patient care and ensure high quality of any future clinical studies.

Key Points

- In patients with COVID-19 and neurological manifestations, neuroimaging should be performed in order to detect underlying causal pathology.

- The basic MRI recommended protocol includes T2-weighted, FLAIR (preferably 3D), and diffusion-weighted images, as well as haemorrhage-sensitive sequence (preferably SWI), and at least for the initial investigation pre and post-contrast T1 weighted-images.

- 3D FLAIR should be acquired after gadolinium administration in order to optimise the detection of leptomeningeal contrast enhancement.
\end{abstract}

Keywords COVID-19 $\cdot$ MRI $\cdot \mathrm{CT} \cdot$ Neuroimaging

\begin{tabular}{l} 
This paper is endorsed by the European Society of Neuroradiology \\
\hline $\begin{array}{l}\text { Stéphane Kremer and Simonetta Gerevini contributed equally to } \\
\text { this work. }\end{array}$
\end{tabular}

Stéphane Kremer

stephane.kremer@chru-strasbourg.fr

1 Hôpitaux Universitaires de Strasbourg, Service d'imagerie 2, Hôpital de Hautepierre, Strasbourg, France

2 Engineering Science, Computer Science and Imaging Laboratory (ICube), Integrative Multimodal Imaging in Healthcare, UMR 7357, University of Strasbourg-CNRS, Strasbourg, France

3 Neuroradiology Unit, ASST Papa Giovanni XXIII, Bergamo, Italy

4 Sección de Neurorradiología, Hospital Universitario, 12 de Octubre, Madrid, Spain

\author{
Abbreviations \\ ACA Anterior cerebral artery \\ ARDS Acute respiratory distress syndrome \\ CMB Cerebral microbleeds \\ CT Computed tomography
}

5 Neuroradiological Academic Unit, Queen Square UCL Institute of Neurology, London, Great Britain

6 Lysholm Department of Neuroradiology, The National Hospital for Neurology and Neurosurgery, London, Great Britain

7 Department of Radiology \& Nuclear Medicine, Department of Epidemiology, Erasmus MC University Medical Center, Rotterdam, The Netherlands

8 Department of Neuroradiology, IRCCS San Raffaele, Scientific Institute and Vita-Salute San Raffaele University, Milan, Italy 


$\begin{array}{ll}\text { CTA } & \text { CT angiogram } \\ \text { CTP } & \text { CT perfusion } \\ \text { CTV } & \text { CT venogram } \\ \text { CVT } & \text { Cerebral venous thrombosis } \\ \text { FCA } & \text { Focal cerebral arteriopathy } \\ \text { FLAIR } & \text { Fluid-attenuated inversion recovery } \\ \text { ICH } & \text { Intracranial haemorrhage } \\ \text { MCA } & \text { Middle cerebral artery } \\ \text { MRA } & \text { MR angiography } \\ \text { OB } & \text { Olfactory bulb } \\ \text { OC } & \text { Olfactory cleft } \\ \text { SOFL } & \text { Self-reported olfactory function loss } \\ \text { SWI } & \text { Susceptibility weighted imaging } \\ \text { VITT } & \text { Vaccine-induced immune thrombotic } \\ & \text { thrombocytopenia }\end{array}$

\section{Introduction}

Neurological manifestations in patients with COVID-19 were first reported by Mao Ling et al. at the beginning of the outbreak in China [1]. Since then, the spectrum of neurological manifestations in SARS-CoV-2 infection has been enlarged and has been widely described [2]. It ranges from central nervous system manifestations (most prominently dizziness, headache, impaired consciousness, acute stroke), peripheral nervous system manifestations (most frequently anosmia, dysgeusia, Guillain-Barré syndrome) to skeletal muscle manifestations [2]. During the current COVID-19 pandemic, vascular complications associated with SARS$\mathrm{CoV}-2$ infection have been detected early on, and they have been mostly classified as thrombotic events [3].

The most relevant neurological thrombotic event is stroke, in particular ischaemic stroke [4]. The association between SARS-CoV-2 infection and stroke appears clear, and from a chronological point of view, it seems to occur close to the time of infection: median delay of stroke from COVID-19 symptoms onset is $8.8(6.3-11.6)$ days [4].

The exact incidence of neurological manifestations is very difficult to establish as patients' inclusion criteria in the different studies are highly variable [2]. Furthermore, available evidence so far consists mostly of case reports, small case series, and some retrospective observational studies, and the frequency of symptoms may vary worldwide.

However, neurological manifestations seem to be more frequent in severe COVID-19 infection, in the presence of comorbidities, and in patients with multi-organ failure [5, 6]. They also seem associated with a worse prognosis with higher mortality $[7,8]$.

Available imaging data are very heterogeneous across institutions, countries, and clinical settings, which makes it difficult to draw generalizable conclusions regarding the neuroimaging manifestations in COVID-19. For future research and clinical practice, standardisation of image acquisition and reporting would be very beneficial.

A NeuroCovid working group constituted of experts in the field of imaging in COVID-19 infections, inflammatory disorders, or stroke has been constituted under the aegis of the Subspecialty Committee on Diagnostic Neuroradiology of the European Society of Neuroradiology (ESNR).

The current NeuroCovid working group's objectives are to address the standardisation of the imaging, follow-up, and reporting of neuro-imaging (of the brain, spine, as well as peripheral nervous system) in patients who have COVID-19 and neurological manifestations and to issue neuroimaging recommendations. Below we present the experts' opinions based on the best currently evidence.

\section{Neuro-imaging indications (diagnosis and follow-up, MRI and CT) in patients with COVID-19}

Since the first report by Poyiadji $\mathrm{N}$ et al. of acute necrotizing encephalopathy lesions in a patient with COVID-19 [9], many other neuroradiological abnormalities have been reported [10-13]. There is little doubt about the usefulness of neuroimaging in patients with acute symptoms, but true incidence of neuroradiological findings is difficult to assess because of studies' methodological heterogeneity.

Raman et al. demonstrated that patients with initially moderate to severe COVID-19 requiring hospitalisation, at 2-3 months from disease onset exhibited impaired cognitive performance, specifically in the executive and visuospatial domains [15].

Some patients referred as having "long COVID" have ongoing clinical symptoms at least 1 month after SARSCoV-2 infection, including neurological manifestations such as cognitive dysfunction or headache [16-21]. Cognitive dysfunction is reported in $85 \%$, and memory impairments in $73 \%$ of "long COVID patients." In these cases structural MRI does frequently not demonstrate any significant COVID-related abnormalities [22]. At present the role of neuroimaging in long COVID patients is therefore mainly the exclusion of other, potentially treatable, coexisting conditions. Neuroimaging correlates of long COVID in studies using advanced and functional imaging are presently uncertain, and are subject of ongoing research.

As symptoms can evolve, and new symptoms can arise over time, it is difficult to be certain about the exact incidence of "long COVID," and the underlying pathophysiology remains largely unknown. Different hypotheses have been evoked like virus persistence, reinfection, immune 
dysregulation and systemic inflammation, or post-traumatic stress $[23,24]$.

R. In patients with COVID-19 and neurological manifestations, neuroimaging, either CT or MRI, may be performed at least once during the acute phase in order to detect underlying causal pathology.

If an initial CT does not provide an explanation for the neurological symptoms, an MRI may be performed before concluding that neuroimaging is negative

$R$. In patients with initial abnormal neuroimaging findings, a follow-up MRI may be advised between 3 and 6 months following initial neurological manifestations in order to document any residual lesions as well as resolution or progression of initial lesions.

$R$. In patients with long COVID, neuroimaging, either CT or MRI, can be performed in order to exclude any other conditions that may coexist of gross sequelae of COVID-infection.

\section{Position of CT imaging}

For acute stroke, brain CT is, in most centres, the imaging modality of choice for diagnosis and patient triage for treatment. Early diagnostic management of stroke in COVID follows the general AHA recommendations where $\mathrm{CT}$ in the acute phase has achieved a recommendation of Class I with an evidence of Level A [25].

This is mainly related to the ability of CT to rule out intracranial haemorrhage ( $\mathrm{ICH})$, which is less frequent than ischaemic stroke in COVID-19 patients [26], but more often lobar and multifocal than in non-COVID-related ICH [27]. In severe cases of patients presenting complicated acute respiratory distress syndrome (ARDS) and COVID-19, brain CT has demonstrated the presence of cortical and subarachnoid haemorrhages possibly related to distal endothelial capillary stress and vascular fragility [28].

Studies of COVID-19 stroke patients report the presence of extensive thrombi in the supra-aortic vessels on CTangiograms (CTAs), while involvement of small vessels is less frequent [4]. The most frequent COVID-related stroke pattern is large vessel occlusion often involving multiple arterial territories [4]. It is, however, noteworthy that the prevalence of small vessel (lacunar) infarcts is likely to be underestimated in studies using (or including CT) compared with those using MRI with diffusion weighted imaging.

A CT venogram (CTV) is indicated if there is a suspicion of cerebral venous thrombosis (CVT), either clinically or on non-enhanced CT [29].
Shahjouei et al. [30] showed a prevalence of CVT in 6/156 (4\%) COVID-19 patients with a stroke presentation in a multicentre study.

A recent study of 13,500 patients [31] showed that the incidence of CVT in patients with COVID-19 is around 8.8 per 10,000, which is rare but higher than expected in the general population.

As for non COVID stroke, the role of CTP is established with a Class I level A evidence for selecting candidates for mechanical thrombectomy between 6 and $24 \mathrm{~h}$ [25].

Findings of non-stroke brain lesions on CT in neurologically compromised COVID-19 patients have been less frequently reported. Nevertheless, COVID-related posterior reversible encephalopathy syndrome (PRES) cases have been detected with CT and CTA [32], and COVID-related encephalopathies also were diagnosed using brain CT imaging, prompting more detailed MRI studies [33].

R. In patients with COVID-19 and clinical stroke symptoms, brain CT may be the first modality of choice to rule out haemorrhage. CT, together with CTA, helps clinicians to make an appropriate triage for endovascular treatment. In selected cases where extension of the time window for treatment is considered or where the time of onset of symptoms is uncertain, CT perfusion $(C T P)$ is recommended.

$R$. In cases of acute neurological complications during hospitalisation for COVID-19, CT can represent the first diagnostic step to rule out potentially treatable lesions and/or address the need for further brain imaging with MRI.

R. CTV should be considered in patients with symptoms of cerebral venous thrombosis or with stroke symptoms but without signs of arterial ischaemia on CT/CTA.

\section{Recommended MRI protocol in order to investigate patients with COVID-19 and neurological manifestations}

We can suggest a basic protocol, with a minimum required sequences to explore the brain of patients with COVID-19 and neurological symptoms.

Multimodality MRI in the exploration of patients with acute and chronic neurological manifestations and COVID-19: Perfusion weighted Imaging, particularly Arterial Spin Labelling, Diffusion Tensor Imaging, spectroscopy, functional MRI, in particular, resting-state fMRI, are part of research investigations in patients with 
COVID-19. However, their contribution in routine clinical examination has not been proven yet.

\begin{tabular}{|c|c|}
\hline Recommended MRI protocol & Aims \\
\hline Diffusion-weighted imaging & $\begin{array}{l}\text { Detection of acute ischaemic } \\
\text { lesions }\end{array}$ \\
\hline SWI (rather than T2* GRE) & $\begin{array}{l}\text { Detection of: } \\
\text { - cerebral microbleeds } \\
\text { - hemosiderin depositions } \\
\text { - cortical vein thrombosis }\end{array}$ \\
\hline $3 D$ TOF MRA & $\begin{array}{l}\text { Detection of arterial occlusion or } \\
\text { stenosis }\end{array}$ \\
\hline \multicolumn{2}{|l|}{ T1 before gadolinium injection } \\
\hline $\begin{array}{l}\text { Post-gadolinium } 3 D \text { FLAIR } \\
\text { (rather than } 2 D \text { ) }\end{array}$ & $\begin{array}{l}\text { Detection of leptomeningeal con- } \\
\text { trast enhancement }\end{array}$ \\
\hline $\begin{array}{l}\text { Post-gadolinium } 3 D G E T 1 \\
\text { (rather than } 2 D \text { ) }\end{array}$ & $\begin{array}{l}\text { Detection of intracerebral contrast } \\
\text { enhancement and to exclude } \\
\text { cerebral venous thrombosis }\end{array}$ \\
\hline \multicolumn{2}{|l|}{ Optional sequences } \\
\hline $3 D-C I S S T 2 W I$ & Olfactory bulb exploration \\
\hline Coronal 3D T2 STIR & Plexus exploration \\
\hline $\begin{array}{l}\text { Sagittal T2 STIR and post- } \\
\text { gadolinium T1 }\end{array}$ & Spinal cord exploration \\
\hline $\begin{array}{l}\text { Black blood imaging } \\
\text { sequences }\end{array}$ & Vessel wall exploration \\
\hline
\end{tabular}

More detailed consideration regarding specific sequences is now given in the subsequent paragraphs.

\section{SWI: microbleeds}

Focal areas of susceptibility artifact on SWI or T2* weighted images, largely assumed to represent cerebral microbleeds (CMB), are a common finding on brain MRI studies of critically ill patients with COVID-19 on ventilator support, with long and pronounced respiratory failure, with higher peak D-dimer levels, and disturbance of consciousness and confusion [34-37].

These SWI lesions can be punctate, ovoid, or nonspherical (linear) in shape and vary in number from few to uncountable and have a predilection for involving the corpus callosum (particularly the splenium), juxtacortical U-fibres, and main white matter tracts, such as the internal capsules and middle cerebellar peduncles. It is important to note that CT in these patients, even retrospectively, did not reveal any punctate microhaemorrhages. When a high number of microbleeds are present, they can be associated with focal reduced diffusion and/or confluent T2/FLAIR hyperintensities.

There are various possible explanations for these findings including true microbleeds, as well as intravascular microthrombi and stagnant flow of deoxyhaemoglobin-rich blood in small arteries and veins, especially if their shape is more linear. Several pathophysiological mechanisms have been evoked for these lesions, including hypoxia, ischaemia, inflammation, thrombosis, endothelial injury, or a combination of these [38-40].

These lesions are also associated with increased mortality and worse functional outcome in patients with COVID19 , so probably these SWI lesions are late complications of critically ill patients with COVID-19 and likely related to hypoxemia [41].

R. MR with SWI should be performed in critically ill COVID-19 patients with neurological symptoms. Presence of micro bleeds may predict worse outcome in these patients. SWI is preferable to $T 2 *$-weighted images which are less sensitive to $C M B$ detection.

\section{R. CT is not useful for the detection of microhaemorrhages.}

\section{Post gadolinium 3D FLAIR: leptomeningeal contrast enhancement}

Leptomeningeal contrast enhancement has been described at the beginning of the outbreak in patients with severe COVID-19 and neurological symptoms and has since been confirmed in larger series of patients [11, 36, 37, 42].

Leptomeningeal contrast enhancement can be either limited and localised or diffuse.

The exact incidence in COVID-19 is unknown (up to $17 \%$ in the study by Kremer et al.) [43] but is greatly dependent on the MRI protocol. Indeed, the detection requires contrast media administration and is most optimally seen on postgadolinium FLAIR images. Like in other leptomeningeal pathologies (tumoural, infectious, or inflammatory), post gadolinium FLAIR images are more sensitive than post gadolinium T1-weighted images to detect leptomeningeal contrast enhancement, particularly if the acquisition is delayed after gadolinium injection [44-47].

Leptomeningeal contrast enhancement seems to correspond to an inflammatory process with lymphohistiocytic infiltration rather than a direct infectious process, as demonstrated in neuropathological studies [48, 49].

R. Contrast-enhanced 3D FLAIR acquisition may be suggested in imaging of COVID-19 patients because it may be more sensitive than contrast-enhanced T1-weighted imaging for detection of leptomeningeal enhancement.

\section{Vascular imaging: vessel wall imaging and MR angiographic studies}

COVID-19-associated vasculitis and vasculopathy have been described as one of the defining features of virusinduced systemic disease with multi-organ involvement, based on post-mortem studies [50]. In the context of 
COVID-19, there have so far been only very few reports describing MR angiography (MRA) findings and vessel wall enhancement, indicative of vasculitis or post-viral vasculopathy. The true prevalence of vasculitis in this condition remains unknown, as high resolution in MRA and dedicated vessel wall imaging are not routinely performed in COVID-19 patients with neurological symptoms.

Dixon et al. [51] described a case of a 64-year-old patient with COVID-19 pneumonia on mechanical ventilation, inotropic support, and haemofiltration, who failed to be responsive following sedation hold. MRI showed multi-territory arterial infarcts, and a postcontrast T1 SPACE MRI sequence demonstrated pathological concentric vessel wall enhancement of both middle cerebral (MCA), anterior cerebral (ACA), vertebral arteries, and the basilar arteries, which responded to immunosuppressive treatment with resolution of the vessel wall enhancement in the MCA and ACA and reduced vertebrobasilar enhancement.

Lersy et al. [52] found arterial vessel wall thickening and concentric enhancement, suggestive of vasculitis, in 11/ 69 patients (16\%) in a consecutive cohort of COVID-19 patients on the intensive care unit, undergoing a brain MRI, most commonly involving the middle cerebral, basilar, and posterior cerebral arteries.

Subsequently, Uginet et al. [53] used MRA and high-resolution vascular black blood sequences in 34 patients with COVID-19 encephalopathy. They detected circular enhancement and thickening of the basilar and vertebral arteries in $85 \%$ of cases without any evidence of associated arterial narrowing on MRI angiography and any infarcts in the corresponding arterial territories.

Further evidence of a vasculitic processes in COVID-19 patients comes from a recent nuclear medicine study by Sollini et al. [54], who used $\left[{ }^{18} \mathrm{~F}\right] \mathrm{FDG}-\mathrm{PET} / \mathrm{CT}$ in patients with "long COVID" and detected a mild to moderate $\left[{ }^{18} \mathrm{~F}\right] \mathrm{FDG}$ uptake in vessels for $61 \%$ of their patients.

From the above studies, it is clear that vasculitis in COVID-19 may be more frequent than suspected initially. It is of note that vessel wall enhancement is not necessarily associated with the luminal narrowing on MRA. A normalappearing MRA does, therefore, not exclude COVID-19-associated vasculitis.

However, care has to be taken to use dedicated "black blood" vessel wall imaging sequences with complete saturation flowing spins, as ordinary post-contrast $\mathrm{T} 1$ weighted spin-echo sequences may give false-positive results due to the enhancement of slow intraluminal flow. Furthermore, one has to be aware of the pitfall of physiological enhancement of the vasa vasorum in proximal intracranial vessels.

It remains at present an open question in which clinical scenarios dedicated black blood vessel imaging sequences, in addition to MRA should be recommended.
Otherwise, unexplained arterial infarcts may represent such an indication.

If there is a suspicion of cerebral venous thrombosis, an MR venogram (MRV) can be performed instead of a CTV (see discussion above). Most cases of acute/subacute venous sinus thrombosis also show "blooming artifact" on SWI sequences.

It is currently emerging that venous thrombosis can also be a complication of vaccine-induced immune thrombotic thrombocytopenia (VITT) [55]. This is likely to prompt an increased use of CT and MR venograms.

\section{$R$. Intracranial MRA should routinely be performed in stroke patients in whom MR is the initial imaging modality (which is the minority of cases), and in whom a vasculitic process is suspected. A normal vessel cali- bre on MRA does, however, not exclude a vasculitis.}

\begin{abstract}
R. Black blood vessel wall imaging should only be performed in selected patients with COVID-19 in whom there is a strong clinical or radiological suspicion that lesions could be secondary to a vasculitic rather than thrombotic/embolic process.
\end{abstract}

\section{$R$. In many centres, CTV is the first-line investigation in patients with suspected CVT, but MRV represents an alternative and SWI may be more sensitive in detecting isolated cortical vein thrombosis.}

\section{Peripheral nervous system: olfactory bulb, plexus}

Isolated anosmia/hyposmia is reported as a typical symptom of COVID-19 infection [56]. The prevalence of selfreported olfactory function loss (SOFL) among SARSCoV-2-infected patients is around $52.7 \%$ [57]. However, a quantitative olfactory deficit is observed in a greater proportion of patients using objective olfactory function tests [58]. Most cases experience a quick recovery of olfactory disorders [59]. Long-lasting impairment of smell is, however, possible [60].

The link between olfactory disorders and viral damage to the neurosensory tract is still debated. A recent work [61] demonstrated that SARS-CoV-2 can enter the nervous system by crossing the neural-mucosal interface in olfactory mucosa, exploiting the close vicinity of olfactory mucosal, endothelial, and nervous tissue, including delicate olfactory and sensory nerve endings.

Although olfactory impairment in COVID-19 patients has been largely documented, only a few reports of olfactory bulbs (OB) imaging abnormalities are available, most of them focusing on the acute disease stage [62, 63].

Bilateral inflammatory obstruction of the olfactory clefts (OC) was observed on MR imaging of the nasal cavity of a 
COVID-19 patient, but no anomalies of the olfactory bulbs and tracts [56]. Another study reported a case with anosmia evaluated with 3D-CISS T2WI, which demonstrated severe enlargement and abnormal high signal intensity on $\mathrm{T} 2$, being interpreted as bilateral olfactory bulb oedema and also olfactory cleft mild oedema. The follow-up MR imaging (D24) showed a reduction in the volume of the bulbs [64].

As pointed out by Shor et al. [65], signal intensity of olfactory bulbs can vary with field strength, the MR vendor and the acquisition parameters of T2-FLAIR sequences. Furthermore, it has previously been reported that OBs could appear hyperintense on T2-FLAIR in healthy subjects [66]. For these reasons, T2-FLAIR signal intensity should be compared with the surrounding structures, such as the cortex or the optic nerves, and possibly quantified.

Enhancement of olfactory bulbs following gadolinium injection has been described in a few cases [67]. Case reports of olfactory bulb atrophy in COVID-19 patients with persistent anosmia have been described $[68,69]$. It should be noted that in all the literature the intensity of olfactory bulbs has been defined as normal when the bulbs had the same intensity as cortex, as typically seen in healthy controls. Abnormal olfactory bulb intensity is defined when the bulbs are more hyperintense than the cortex on T1WI and/or STIR. After gadolinium injection on T1WI, and more easily on T1 W Fat Sat, enhancement of the olfactory bulbs is defined when they become more hyperintense in comparison with their intensity on pre-gadolinium T1WI. However, when there is only the post-gadolinium T1WI and the bulb is more hyperintense than the normal cortex, this represents olfactory bulb intensity abnormality and maybe an enhancement or microbleeding (methaemoglobin); for this reason, acquiring a post contrast 3D FLAIR can give a more reliable interpretation of the presence/absence of focal enhancement of the OB.

Some degree of degeneration of the OB has been confirmed in a small cohort of anosmic COVID-19 patients studied with both paranasal CT and MRI [70]. Future studies may evaluate changes in olfactory bulb volume in larger cohorts of COVID-19 patients at multiple timepoints with supplementary objective psychophysical olfactory function testing.

It is not so clear if the loss of the sense of smell related to COVID-19 is reversible or irreversible. It appears to last between 8 and 9 days on average, but can go on for several weeks for some patients, and in some studies last for many months. Some authors demonstrated that olfactory training (repeat and deliberate sniffing of a set of odorants) demonstrated improved olfaction. Others used oral and intranasal corticosteroids to exclude an inflammatory component in patients with postinfectious OD. However, corticosteroids are not currently recommended for individuals treatments. Other medications that have shown promise in postinfectious olfactory dysfunction include intranasal sodium citrate, which is thought to modulate olfactory receptor transduction cascades; intranasal vitamin A, which may act to promote olfactory neurogenesis; and systemic omega- 3 , which may act through neuroregenerative or anti-inflammatory means $[71,72]$. However, to date, there is no evidence that these therapies are effective in patients with OD related to COVID-19.

There is an increased incidence of Guillain-Barré syndrome during the COVID-19 outbreak; this has been published first as case reports then as case series, for example in Italy [73]. It is not easy to demonstrate a causal relationship but recent papers seem to support a pathogenic link and or a familial occurrence of Guillain-Barré syndrome after COVID-19 infection.

There is a growing evidence of brachial plexus involvement during COVID-19 infection [74]. Peripheral nerve injuries may be associated with prone positioning on intensive care units, although other mechanisms, such as those of a neuroinflammatory nature, cannot be excluded, like true Parsonage Turner Syndrome [75], although literature is still poor. Gadolinium injection can be helpful in the differential diagnosis of brachial plexopathy, as it can show denervation enhancement more or less associated with muscular oedema [76]. Patients with lesion of the brachial plexus had severe weakness and numbness with axonometic electrodiagnostic findings.

\section{R. Consider performing MR imaging of $O B$ and $O C$ in all COVID-19 patients with SOFL.}

R. To obtain $O B$ volume segmentation, 3D-T2 coronal images with high resolution (CISS and similar) may be suggested. Coronal FLAIR images may be used to detect signal abnormalities.

\section{Spinal cord}

Acute transverse myelitis cases have been reported in the literature [76], mostly as single case reports. Due to the heterogeneity of published data, underlying causality is difficult to be easily inferred.

There was a slight male predominance $(60 \%)$ with a median age of 56 years [77]. Neurological symptoms first manifested after a mean of 10.3 days from the respiratory symptoms [77]. MRI demonstrated mainly longitudinally extensive lesions who spanned 9.8 vertebral segments, or less frequently short-segment lesions [76, 77]. Necrotichaemorrhagic transformation was rare [77]. CSF was infrequently positive for SARS-CoV-2 but demonstrated in 3/4 of cases inflammatory abnormalities [76, 77].

The underlying pathophysiological mechanism remains unknown, but a para-infectious or post-infectious immunemediated aetiology seems possible [78]. 
However, cases of spinal cord ischaemia have also been reported during COVID-19 infection, but the causal relationship remains unknown [79].

$R$. Consider performing MR imaging of the spinal cord in patients with spinal cord main clinical presentation but also in patients with brain demyelinating lesions.

\section{Proposal of structured reporting of MRI}

(1) State what sequences and specifically whether SWI (of $\mathrm{T} 2 *)$ and post-contrast sequences were performed.

(2) If the study is normal: "Normal study with no evidence of acute or chronic infarcts, microbleeds or white matter lesions."

(3) If abnormal, start with the predominant abnormality (stroke/haemorrhage/white or grey matter lesions) and then go systematically through the remainder of the checklist below:

\begin{tabular}{|c|c|c|}
\hline & Presence (yes/no) & If yes-describe further \\
\hline$\sqrt{ }$ & Infarct & $\begin{array}{l}\text { Acute, subacute, chronic } \\
\text { Cortical, subcortical, small } \\
\text { vessel, single/multiple, sin- } \\
\text { gle/multiple territories }\end{array}$ \\
\hline$\sqrt{ }$ & Macrohaemorrhage & $\begin{array}{l}\text { parenchymal, subdural, suba- } \\
\text { rachnoid, } \\
\text { single/multiple, central/periph- } \\
\text { eral }\end{array}$ \\
\hline$\sqrt{ }$ & $\begin{array}{l}\text { Cerebral microbleeds } \\
\quad(\mathrm{CMB})\end{array}$ & $\begin{array}{l}\text { 1-4; 5-10;>10 (numerous) } \\
\text { central/peripheral; involving } \\
\text { (yes/no): corpus callosum, } \\
\text { internal capsules, middle } \\
\text { cerebellar peduncles }\end{array}$ \\
\hline$\sqrt{ }$ & $\begin{array}{l}\text { White matter hyperin- } \\
\text { tensities }\end{array}$ & $\begin{array}{l}\text { well defined/ill-defined/conflu- } \\
\text { ent/location } \\
\text { restricted/non-restricted dif- } \\
\text { fusion } \\
\text { enhancing/non-enhancing } \\
\text { haemorrhagic/non-haemor- } \\
\text { rhagic } \\
\text { further specify if possible: e.g. } \\
\text { likely to be incidental SVD, } \\
\text { ADEM like/CLOCC like }\end{array}$ \\
\hline$\sqrt{ }$ & Grey matter lesions & $\begin{array}{l}\text { Cortical/deep nuclei } \\
\text { Hippocampal/extra-hippocam- } \\
\text { pal } \\
\text { swelling/no swelling } \\
\text { restricted/ non-restricted dif- } \\
\text { fusion } \\
\text { haemorrhagic/non-haemor- } \\
\text { rhagic }\end{array}$ \\
\hline$\sqrt{ }$ & $\begin{array}{l}\text { Leptomeningeal } \\
\text { involvement }\end{array}$ & $\begin{array}{l}\text { Enhancement/FLAIR hyper- } \\
\text { intensity } \\
\text { Focal (less than } 3 \text { sulci)/ dif- } \\
\text { fuse (more than } 3 \text { sulci)/ }\end{array}$ \\
\hline
\end{tabular}

\begin{tabular}{lll}
\hline & Presence (yes/no) & If yes-describe further \\
\hline$\sqrt{ }$ & $\begin{array}{c}\text { Cranial nerve involve- } \\
\text { ment }\end{array}$ & $\begin{array}{l}\text { Enhancement/FLAIR hyper- } \\
\text { intensity } \\
\text { Olfactory nerve/ other cranial } \\
\text { nerves }\end{array}$ \\
$\sqrt{ }$ & Intracranial vessels & $\begin{array}{l}\text { arterial stenosis/thrombosis } \\
\text { venous thrombosis } \\
\text { vessel wall enhancement }\end{array}$ \\
$\sqrt{ }$ & Other relevant findings & \\
\hline
\end{tabular}

\section{Conclusion}

Summarise main findings and state likely aetiology.

Examples of conclusions:

(1) The multiple well-defined white matter hyperintensities are likely to represent ADEM in the context of COVID19 infection.

(2) The multiple peripheral microbleeds, sparing the corpus callosum and internal capsules, could be due to cerebral amyloid angiopathy and are not necessarily related to COVID-19 infection.

Funding The authors state that this work has not received any funding.

\section{Declarations}

Guarantor The scientific guarantor of this publication is Pr. S Kremer.

Conflict of interest The authors declare no competing interests.

Statistics and biometry No complex statistical methods were necessary for this paper.

Informed consent Written informed consent was not required for this study because it is a recommendation article.

Ethical approval Institutional Review Board approval was not required because it is a recommendation article.

Methodology

- Retrospective

- Observational

- Multicentre study

\section{References}

1. Mao L, Jin H, Wang M et al (2020) Neurologic manifestations of hospitalized patients with coronavirus disease 2019 in Wuhan. China JAMA Neurol 77(6):683-690. https://doi.org/10.1001/ jamaneurol.2020.1127 
2. Pezzini A, Padovani A (2020) Lifting the mask on neurological manifestations of COVID-19. Nat Rev Neurol. 16(11):636-644. https://doi.org/10.1038/s41582-020-0398-3

3. Benussi A, Pilotto A, Premi E et al (2020) Clinical characteristics and outcomes of inpatients with neurologic disease and COVID19 in Brescia, Lombardy. Italy Neurology 95(7):e910-e920. https://doi.org/10.1212/WNL.0000000000009848

4. Nannoni S, de Groot R, Bell S, Markus HS (2021) Stroke in COVID-19: A systematic review and meta-analysis. Int J Stroke. 16(2):137-149. https://doi.org/10.1177/1747493020972922

5. Koralnik IJ, Tyler KL (2020) COVID-19: A global threat to the nervous system. Ann Neurol 88(1):1-11. https://doi.org/10.1002/ ana. 25807

6. Iadecola C, Anrather J, Kamel H (2020) Effects of COVID-19 on the nervous system. Cell. 183(1):16-27.e1. https://doi.org/10. 1016/j.cell.2020.08.028

7. Liotta EM, Batra A, Clark JR et al (2020) Frequent neurologic manifestations and encephalopathy-associated morbidity in Covid-19 patients. Ann Clin Transl Neurol. 7(11):2221-2230. https://doi.org/10.1002/acn3.51210

8. Eskandar EN, Altschul DJ, de La Garza Ramos R, et al (2020) Neurologic syndromes predict higher in-hospital mortality in COVID-19. Neurology. https://doi.org/10.1212/WNL.00000 00000011356

9. Poyiadji N, Shahin G, Noujaim D, Stone M, Patel S, Griffith B (2020) COVID-19-associated acute hemorrhagic necrotizing encephalopathy: imaging features. Radiology. 296(2):E119-E120. https://doi.org/10.1148/radiol.2020201187

10. Kremer S, Lersy F, de Seze J et al (2020) Brain MRI findings in severe COVID-19: a retrospective observational study. Radiology. 297(2):E242-E251. https://doi.org/10.1148/radiol.2020202222

11. Chougar L, Shor N, Weiss N et al (2020) Retrospective observational study of brain MRI findings in patients with acute SARSCoV-2 infection and neurologic manifestations. Radiology. 297(3):E313-E323. https://doi.org/10.1148/radiol.2020202422

12. Moonis G, Filippi CG, Kirsch CFE, et al (2020) The spectrum of neuroimaging findings on $\mathrm{CT}$ and MRI in adults with coronavirus disease (COVID-19). AJR Am J Roentgenol. https://doi.org/10. 2214/AJR.20.24839

13. Lindan CE, Mankad K, Ram D et al (2021) Neuroimaging manifestations in children with SARS-CoV-2 infection: a multinational, multicentre collaborative study. Lancet Child Adolesc Health. 5(3):167-177. https://doi.org/10.1016/S2352-4642(20) 30362-X

14. Fernandez CE, Franz CK, Ko JH et al (2021) Imaging review of peripheral nerve injuries in patients with COVID-19. Radiology. 298(3):E117-E130. https://doi.org/10.1148/radiol.2020203116

15. Raman B, Cassar MP, Tunnicliffe EM, et al (2021) Medium-term effects of SARS-CoV-2 infection on multiple vital organs, exercise capacity, cognition, quality of life and mental health, posthospital discharge. EClinicalMedicine 31:100683. https://doi.org/ 10.1016/j.eclinm.2020.100683

16. Carfì A, Bernabei R, Landi F (2020) Gemelli Against COVID-19 Post-Acute Care Study Group. Persistent symptoms in patients after acute COVID-19. JAMA. 324(6):603-605. https://doi.org/ 10.1001/jama.2020.12603

17. Carvalho-Schneider C, Laurent E, Lemaignen A et al (2021) Follow-up of adults with noncritical COVID-19 two months after symptom onset. Clin Microbiol Infect. 27(2):258-263. https://doi. org/10.1016/j.cmi.2020.09.052

18. Gorna R, MacDermott N, Rayner C et al (2021) Long COVID guidelines need to reflect lived experience. Lancet. 397(10273):455-457. https://doi.org/10.1016/S0140-6736(20) 32705-7

19. Ludvigsson JF (2021) Case report and systematic review suggest that children may experience similar long-term effects to adults after clinical COVID-19. Acta Paediatr. 110(3):914-921. https:// doi.org/10.1111/apa.15673

20. Nehme M, Braillard O, Alcoba G, et al (2020) COVID-19 symptoms: longitudinal evolution and persistence in outpatient settings. Ann Intern Med M20-5926. https://doi.org/10.7326/M20-5926

21. Sivan M, Taylor S (2020) NICE guideline on long covid. BMJ 23(371):m4938. https://doi.org/10.1136/bmj.m4938

22. Davis HE, Assaf GS, McCorkell L et al (2021) Characterizing long COVID in an international cohort: 7 months of symptoms and their impact. EClinicalMedicine 101019. https://doi.org/10. 1016/j.eclinm.2021.101019

23. Al-Aly Z, Xie Y, Bowe B (2021) High-dimensional characterization of post-acute sequelae of COVID-19. Nature 594(7862):259 264. https://doi.org/10.1038/s41586-021-03553-9

24. Nalbandian A, Sehgal K (2021) Gupta A et al Post-acute COVID19 syndrome. Nat Med 27(4):601-615. https://doi.org/10.1038/ s41591-021-01283-z

25. Powers WJ, Rabinstein AA, Ackerson T et al (2019) Guidelines for the early management of patients with acute ischemic stroke: 2019 Update to the 2018 Guidelines for the Early Management of Acute Ischemic Stroke: A Guideline for Healthcare Professionals From the American Heart Association/American Stroke Association. Stroke. 50(12):e344-e418. https://doi.org/10.1161/ STR.0000000000000211

26. Yoon BC, Buch K, Lang M et al (2020) Clinical and neuroimaging correlation in patients with covid-19. AJNR Am J Neuroradiol. 41(10):1791-1796. https://doi.org/10.3174/ajnr.A6717

27. Beyrouti R, Best JG, Chandratheva A, Perry RJ, Werring DJ (2021) Characteristics of intracerebral haemorrhage associated with COVID-19: a systematic review and pooled analysis of individual patient and aggregate data. J Neurol. 5:1-11. https://doi. org/10.1007/s00415-021-10425-9

28. Castellano A, Anzalone N, Pontesilli S, Fominskiy E, Falini A (2020) Pathological brain CT scans in severe COVID-19 ICU patients. Intensive Care Med. 46(11):2102-2104. https://doi.org/ 10.1007/s00134-020-06222-Z

29. Nwajei F, Anand P, Abdalkader M et al (2020) Cerebral venous sinus thromboses in patients with SARS-CoV-2 infection: three cases and a review of the literature. J Stroke Cerebrovasc Dis. 29(12):105412. https://doi.org/10.1016/j.jstrokecerebrovasdis. 2020.105412

30. Shahjouei S, Naderi S, Li J, et al (2020) Risk of stroke in hospitalized SARS-CoV-2 infected patients: A multinational study. EBioMedicine 59:102939. https://doi.org/10.1016/j.ebiom.2020. 102939

31. Al-Mufti F, Amuluru K, Sahni R, et al (2021) Cerebral venous thrombosis in COVID-19: a New York Metropolitan cohort study. AJNR Am J Neuroradiol. https://doi.org/10.3174/ajnr.A7134

32. PrinciottaCariddi L, TabaeeDamavandi P, Carimati F et al (2020) Reversible encephalopathy syndrome (PRES) in a COVID-19 patient. J Neurol. 267(11):3157-3160. https://doi.org/10.1007/ s00415-020-10001-7

33. Katal S, Balakrishnan S, Gholamrezanezhad A (2020) Neuroimaging and neurologic findings in COVID-19 and other coronavirus infections: a systematic review in 116 patients. J Neuroradiol. https://doi.org/10.1016/j.neurad.2020.06.007

34. Fitsiori A, Pugin D, Thieffry C et al (2020) COVID-19 is associated with an unusual pattern of brain microbleeds in critically ill patients. J Neuroimaging. 30(5):593-597. https://doi.org/10.1111/ jon. 12755

35. Agarwal S, Jain R, Dogra S et al (2020) Cerebral microbleeds and leukoencephalopathy in critically ill patients with COVID-19. Stroke. 51(9):2649-2655. https://doi.org/10.1161/STROKEAHA. 120.030940

36. Klironomos S, Tzortzakakis A, Kits A et al (2020) Nervous system involvement in coronavirus disease 2019: results from 
a retrospective consecutive neuroimaging cohort. Radiology. 297(3):E324-E334. https://doi.org/10.1148/radiol.2020202791

37. Kandemirli SG, Dogan L, Sarikaya ZT et al (2020) Brain MRI findings in patients in the intensive care unit with COVID-19 infection. Radiology. 297(1):E232-E235. https://doi.org/10.1148/ radiol.2020201697

38. Meinhardt J, Radke J, Dittmayer C et al (2021) Olfactory transmucosal SARS-CoV-2 invasion as a port of central nervous system entry in individuals with COVID-19. Nat Neurosci 24(2):168175. https://doi.org/10.1038/s41593-020-00758-5

39. Radmanesh A, Derman A, Lui YW et al (2020) COVID-19-associated diffuse leukoencephalopathy and microhemorrhages. Radiology. 297(1):E223-E227. https://doi.org/10.1148/radiol.20202 02040

40. Lersy F, Willaume T, Brisset JC et al (2020) Critical illness-associated cerebral microbleeds for patients with severe COVID-19: etiologic hypotheses. J Neurol. 21:1-9. https://doi.org/10.1007/ s00415-020-10313-8

41. Romero-Sánchez CM, Díaz-Maroto I, Fernández-Díaz E et al (2020) Neurologic manifestations in hospitalized patients with COVID-19: The ALBACOVID registry. Neurology. 95(8):e1060 e1070. https://doi.org/10.1212/WNL.0000000000009937

42. Helms J, Kremer S, Merdji H et al (2020) Neurologic features in severe SARS-CoV-2 infection. N Engl J Med. 382(23):22682270. https://doi.org/10.1056/NEJMc2008597

43. Kremer S, Lersy F, Anheim M et al (2020) Neurologic and neuroimaging findings in patients with COVID-19: A retrospective multicenter study. Neurology 95(13):e1868-e1882. https://doi. org/10.1212/WNL.0000000000010112

44. Kremer S, Abu Eid M, Bierry G et al (2006) Accuracy of delayed post-contrast FLAIR MR imaging for the diagnosis of leptomeningeal infectious or tumoral diseases. J Neuroradiol 33(5):285-291. https://doi.org/10.1016/s0150-9861(06)77286-8

45. Zurawski J, Lassmann H, Bakshi R (2017) Use of magnetic resonance imaging to visualize leptomeningeal inflammation in patients with multiple sclerosis: a review. JAMA Neurol 74(1):100-109. https://doi.org/10.1001/jamaneurol.2016.4237

46. Absinta M, Cortese IC, Vuolo L et al (2017) Leptomeningeal gadolinium enhancement across the spectrum of chronic neuroinflammatory diseases. Neurology. 88(15):1439-1444. https://doi. org/10.1212/WNL.0000000000003820

47. Purcell Y, Lecler A, Saragoussi E, Poiron E, Poillon G, Savatovsky J (2020) Neurologic involvement of patients with coronavirus disease 2019: making the most of MRI. Radiology. 297(1):E239. https://doi.org/10.1148/radiol.2020202466

48. Jaunmuktane Z, Mahadeva U, Green A et al (2020) Microvascular injury and hypoxic damage: emerging neuropathological signatures in COVID-19. Acta Neuropathol. 140(3):397-400. https:// doi.org/10.1007/s00401-020-02190-2

49. Von Weyhern CH, Kaufmann I, Neff F, Kremer M (2020) Early evidence of pronounced brain involvement in fatal COVID-19 outcomes. Lancet. 395(10241):e109. https://doi.org/10.1016/ S0140-6736(20)31282-4

50. Becker RC (2020) COVID-19-associated vasculitis and vasculopathy. J Thromb Thrombolysis 50(3):499-511. https://doi.org/ 10.1007/s11239-020-02230-4

51. Dixon L, Coughlan C, Karunaratne K, et al (2020) Immunosuppression for intracranial vasculitis associated with SARS-CoV-2: therapeutic implications for COVID-19 cerebrovascular pathology. J Neurol Neurosurg Psychiatry jnnp-2020-324291. https:// doi.org/10.1136/jnnp-2020-324291

52. Lersy F, Anheim M, Willaume T, et al (2020) Cerebral vasculitis of medium-sized vessels as a possible mechanism of brain damage in COVID-19 patients. J Neuroradiol S0150-9861(20)30287-X. https://doi.org/10.1016/j.neurad.2020.11.004
53. Uginet M, Breville G, Hofmeister J, et al (2021) Cerebrovascular complications and vessel wall imaging in COVID-19 encephalopathy-a pilot study. Clin Neuroradiol 1-7. https://doi.org/10.1007/ s00062-021-01008-

54. Sollini M, Morbelli S, Ciccarelli M, et al (2021) Long COVID hallmarks on [18F]FDG-PET/CT: a case-control study. Eur J Nucl Med Mol Imaging 1-11. https://doi.org/10.1007/ s00259-021-05294-3

55. Scully M, Singh D, Lown R, et al (2021) Pathologic antibodies to platelet factor 4 after ChAdOx1 nCoV-19 vaccination. N Engl J Med. https://doi.org/10.1056/NEJMoa2105385

56. Eliezer M, Hautefort C, Hamel AL et al (2020) Sudden and complete olfactory loss of function as a possible symptom of COVID19. JAMA Otolaryngol Head Neck Surg 146(7):674-675. https:// doi.org/10.1001/jamaoto.2020.0832

57. Tong JY, Wong A, Zhu D, Fastenberg JH, Tham T (2020) The prevalence of olfactory and gustatory dysfunction in covid-19 patients: a systematic review and meta-analysis. Otolaryngol Head Neck Surg 163(1):3-11. https://doi.org/10.1177/01945 99820926473

58. Moein ST, Hashemian SM, Mansourafshar B, Khorram-Tousi A, Tabarsi P, Doty RL (2020) Smell dysfunction: a biomarker for COVID-19. Int Forum Allergy Rhinol. 10(8):944-950. https:// doi.org/10.1002/alr.22587

59. Vaira LA, Hopkins C, Salzano G et al (2020) Olfactory and gustatory function impairment in COVID-19 patients: Italian objective multicenter-study. Head Neck. 42(7):1560-1569. https://doi.org/ 10.1002/hed.26269

60. Hopkins C, Surda P, Vaira LA et al (2021) Six month follow-up of self-reported loss of smell during the COVID-19 pandemic. Rhinology 59(1):26-31. https://doi.org/10.4193/Rhin20.544

61. Meinhardt J, Radke J, Dittmayer C et al (2021) Olfactory transmucosal SARS-CoV-2 invasion as a port of central nervous system entry in individuals with COVID-19. Nat Neurosci 24(2):168175. https://doi.org/10.1038/s41593-020-00758-5

62. Politi LS, Salsano E, Grimaldi M (2020) Magnetic resonance imaging alteration of the brain in a patient with coronavirus disease 2019 (COVID-19) and anosmia. JAMA Neurol 77(8):10281029. https://doi.org/10.1001/jamaneurol.2020.2125

63. Galougahi MK, Ghorbani J, Bakhshayeshkaram M, Naeini AS, Haseli S (2020) Olfactory bulb magnetic resonance imaging in SARS-CoV-2-induced anosmia: the first report. Acad Radiol. 27(6):892-893. https://doi.org/10.1016/j.acra.2020.04.002

64. Laurendon T, Radulesco T, Mugnier J et al (2020) Bilateral transient olfactory bulb edema during COVID-19-related anosmia. Neurology 95(5):224-225. https://doi.org/10.1212/WNL.00000 00000009850

65. Shor N, Chougar L, Pyatigorskaya N (2021) MR imaging of the olfactory bulbs in patients with COVID-19 and anosmia: how to avoid misinterpretation. AJNR Am J Neuroradiol 42(3):E10-E11. https://doi.org/10.3174/ajnr.A6921

66. Chung MS, Choi WR, Jeong HY, Lee JH, Kim JH (2018) MR Imaging-based evaluations of olfactory bulb atrophy in patients with olfactory dysfunction. AJNR Am J Neuroradiol. 39(3):532537. https://doi.org/10.3174/ajnr.A5491

67. Aragão MFVV, Leal MC, CartaxoFilho OQ, Fonseca TM, Valença MM (2020) Anosmia in COVID-19 associated with injury to the olfactory bulbs evident on MRI. AJNR Am J Neuroradiol. 41(9):1703-1706. https://doi.org/10.3174/ajnr.A6675

68. Chiu A, Fischbein N, Wintermark M, Zaharchuk G, Yun PT, Zeineh M (2021) COVID-19-induced anosmia associated with olfactory bulb atrophy. Neuroradiology. 63(1):147-148. https:// doi.org/10.1007/s00234-020-02554-1

69. Liang YC, Tsai YS, Syue LS, Lee NY, Li CW (2020) Olfactory bulb atrophy in a case of COVID-19 with hyposmia. Acad Radiol. 27(11):1649-1650. https://doi.org/10.1016/j.acra.2020.08.016 
70. Kandemirli SG, Altundag A, Yildirim D, TekcanSanli DE, Saatci O (2021) Olfactory bulb MRI and paranasal sinus ct findings in persistent COVID-19 anosmia. Acad Radiol. 28(1):28-35. https:// doi.org/10.1016/j.acra.2020.10.006

71. Chung TW, Zhang H, Wong FK et al (2021) Neurosensory rehabilitation and olfactory network recovery in Covid-19-related olfactory dysfunction. Brain Sci 11(6):686. https://doi.org/10. 3390/brainsci11060686

72. Whitcroft KL, Hummel T (2020) Olfactory dysfunction in COVID-19: diagnosis and management. JAMA 323(24):25122514. https://doi.org/10.1001/jama.2020.8391

73. Filosto M, CottiPiccinelli S, Gazzina S et al (2021) Guillain-Barré syndrome and COVID-19: an observational multicentre study from two Italian hotspot regions. J Neurol Neurosurg Psychiatry. 92(7):751-756. https://doi.org/10.1136/jnnp-2020-324837

74. Miller C, O'Sullivan J, Jeffrey J, Power D (2021) Brachial plexus neuropathies during the COVID-19 pandemic: a retrospective case series of 15 patients in critical care. Phys Ther. 101(1):1pzaa191. https://doi.org/10.1093/ptj/pzaa191

75. Mitry MA, Collins LK, Kazam JJ, Kaicker S, Kovanlikaya A (2021) Parsonage-turner syndrome associated with SARS-CoV2
(COVID-19) infection. Clin Imaging. 72:8-10. https://doi.org/10. 1016/j.clinimag.2020.11.017

76. Barman A, Sahoo J, Viswanath A, Roy SS, Swarnakar R, Bhattacharjee S (2021) Clinical features, laboratory and radiological findings of patients with acute inflammatory myelopathy following COVID-19 infection: a narrative review. Am J Phys Med Rehabil. https://doi.org/10.1097/PHM.0000000000001857

77. Schulte EC, Hauer L, Kunz AB, Sellner J (2021) Systematic review of cases of acute myelitis in individuals with COVID-19. Eur J Neurol. https://doi.org/10.1111/ene.14952

78. Ismail II, Salama S (2021) Association of CNS demyelination and COVID-19 infection: an updated systematic review. J Neurol. 12:1-36. https://doi.org/10.1007/s00415-021-10752-x

79. Bax F, Gigli GL, Iaiza F, Valente M (2021) Spontaneous spinal cord ischemia during COVID-19 infection. J Neurol. 28:1-2. https://doi.org/10.1007/s00415-021-10574-x

Publisher's Note Springer Nature remains neutral with regard to jurisdictional claims in published maps and institutional affiliations. 